Minimum Thickness Requirements for Asphalt Surface Course and Base Layer in Airfield Pavements

Walter R. Barker, Alessandra Bianchini, E. Ray Brown,

August 2011

and Carlos R. Gonzalez

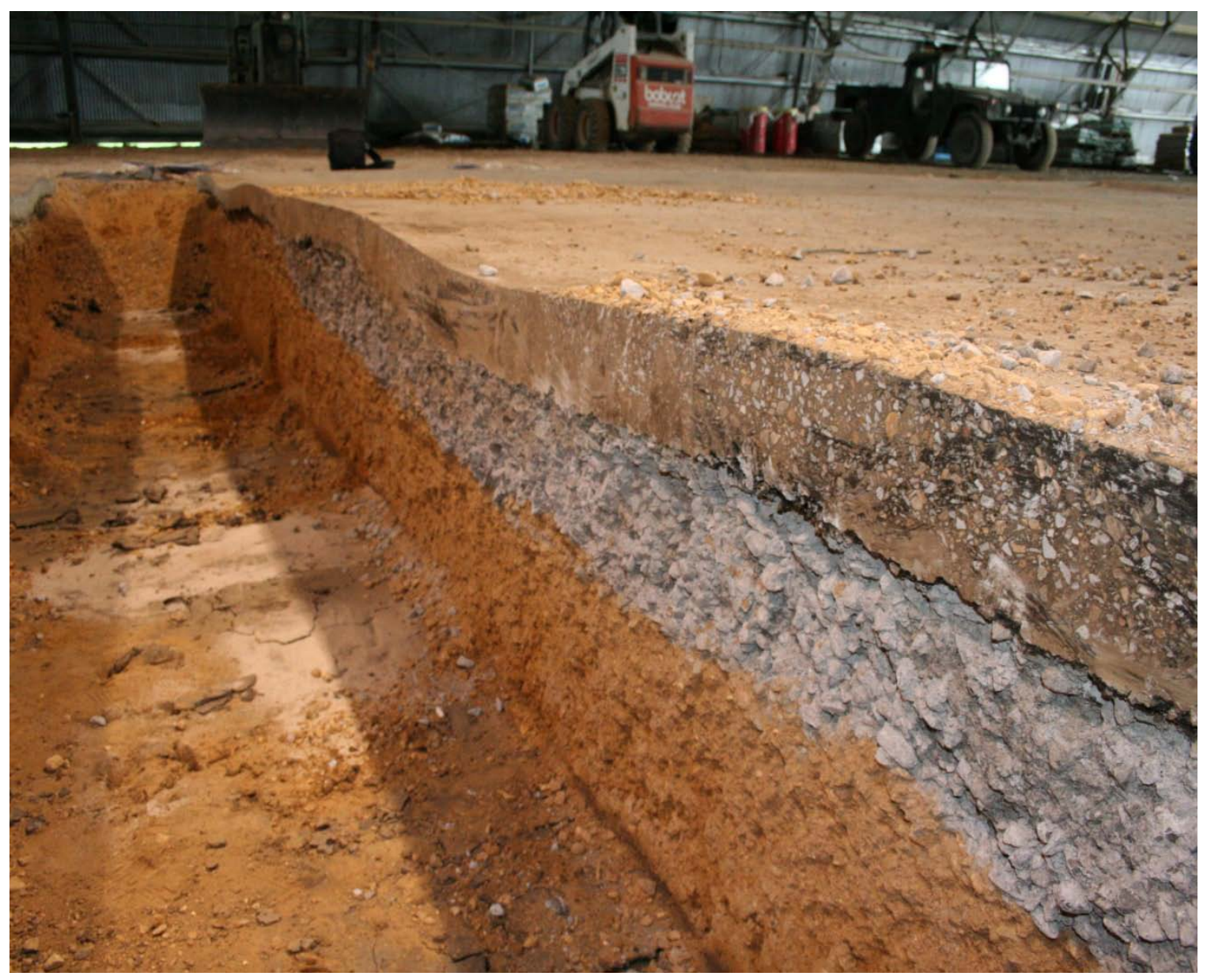




\section{Minimum Thickness Requirements for Asphalt Surface Course and Base Layer in Airfield Pavements}

Walter R. Barker, Alessandra Bianchini, E. Ray Brown, and Carlos R. Gonzalez

Geotechnical and Structures Laboratory

U.S. Army Engineer Research and Development Center 3909 Halls Ferry Road

Vicksburg, MS 39180-6199

Final report

Approved for public release; distribution is unlimited.

Prepared for Headquarters, U.S. Army Corps of Engineers

Washington, DC 20314-1000 


\begin{abstract}
In designing flexible pavements for military airfields, minimum thicknesses of surface and base courses are given in the Unified Facilities Criteria (UFC) in tabular form based on the aircraft type, traffic area, and base California Bearing Ratio (CBR). With the development of larger and heavier aircraft, the minimum thickness requirements were simply adjusted upward through an empirical approach. In this report, the U.S. Army Engineer Research and Development Center (ERDC) research team proposes a rational methodology for determining minimum thicknesses for airfield pavements. The proposed procedure considers aircraft wheel loads, tire pressure, load repetitions, and the CBR of both base and subbase layers. In addition to presenting the methodology for determining layer minimum thicknesses from a structural standpoint, the manuscript briefly presents an examination of the effects of construction methods and materials on minimum thickness. Construction equipment and asphalt material characteristics directly influence the thickness of asphalt layer that can be constructed and its performance when subjected to traffic and the environment.
\end{abstract}

DISCLAIMER: The contents of this report are not to be used for advertising, publication, or promotional purposes. Citation of trade names does not constitute an official endorsement or approval of the use of such commercial products. All product names and trademarks cited are the property of their respective owners. The findings of this report are not to be construed as an official Department of the Army position unless so designated by other authorized documents. 


\section{Contents}

Figures and Tables............................................................................................................................................iv

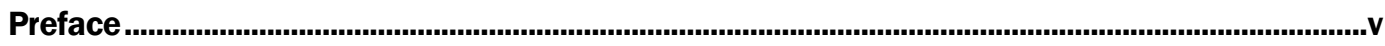

Unit Conversion Factors ..............................................................................................................................vi

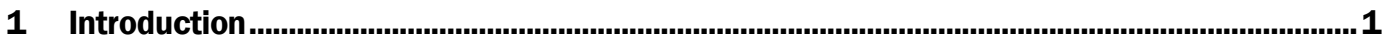

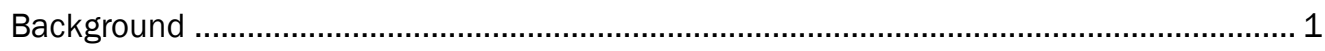

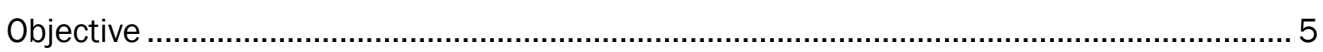

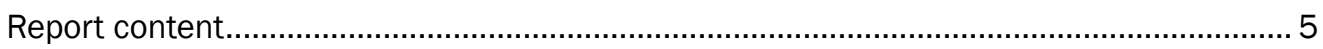

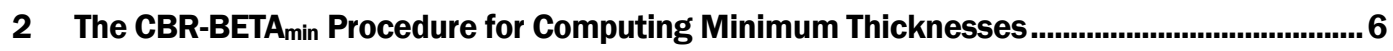

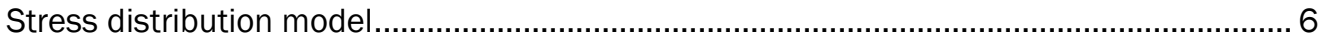

Criteria development for the CBR-BETAmin design procedure .......................................... 7

Methodology for minimum thickness........................................................................... 9

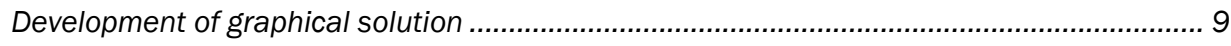

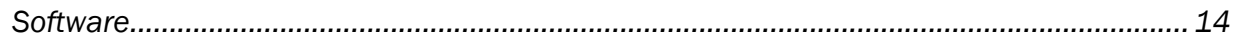

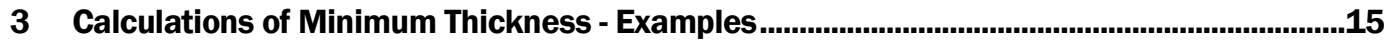

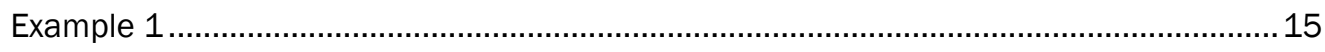

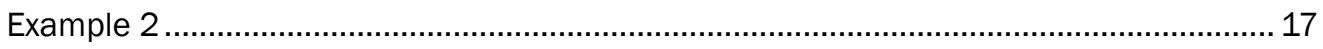

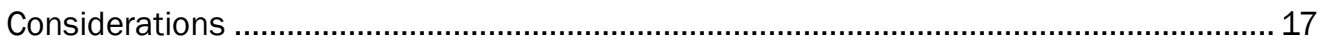

4 Minimum Asphalt Thickness Based on Construction and Environmental ...............................20

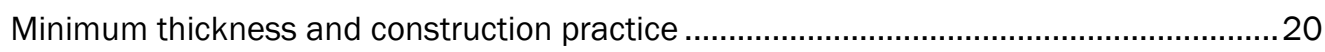

Minimum thickness and environmental issues............................................................... 21

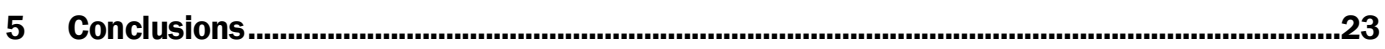

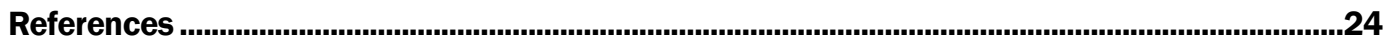

\section{Report Documentation Page}




\section{Figures and Tables}

\section{Figures}

Figure 1. Criteria for minimum thickness...................................................................................... 8

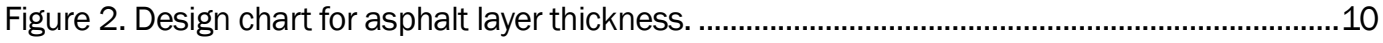

Figure 3. Design chart for base layer $\left(t_{A} / R=0.25\right)$.....................................................................11

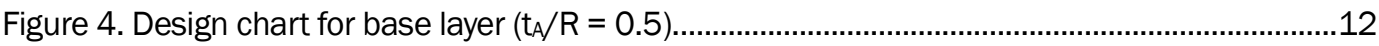

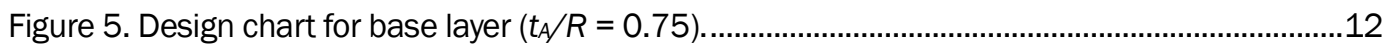

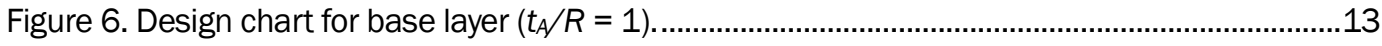

Figure 7. Design chart for base layer $\left(t_{A} / R=1.5\right)$......................................................................13

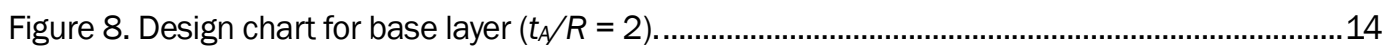

\section{Tables}

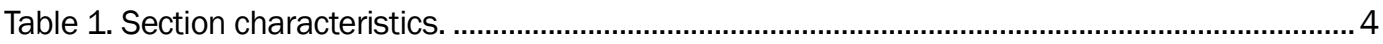

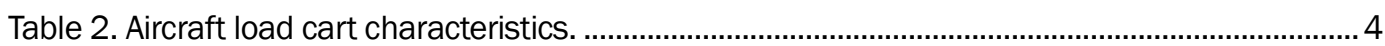

Table 3. Sections, number of passes, and coverages to failure.

Table 4. Asphalt thickness data for Example 1................................................................................16

Table 5. Base thickness data for Example 1. .............................................................................17

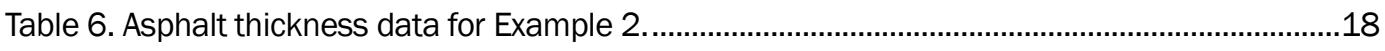

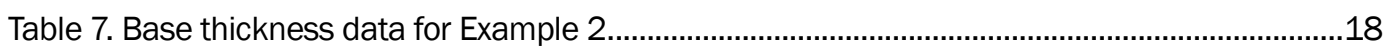

Table 8. Aircraft characteristics. ..............................................................................................19

Table 9. Comparison of UFC minimums with computed minimums.................................................19 


\section{Preface}

The proposed approach for determining layer minimum thickness was developed in conjunction with the development of PCASE, software for pavement design. This approach provides an answer to the empirical approach through the formulation of a rational methodology to address minimum thicknesses for airfield pavements.

The findings and recommendations presented in this report are derived from the analysis of the CBR-BETA design procedure and data from past full-scale testing. The minimum thickness requirements outlined in the Unified Facilities Criteria 3-260-02 were also taken into consideration to refine the proposed approach.

Personnel of the U.S. Army Engineer Research and Development Center (ERDC), Geotechnical and Structures Laboratory (GSL), Vicksburg, MS, prepared this publication. The ERDC research team consisted of Dr. Walter Barker, Carlos R. Gonzalez, E. Ray Brown, and Dr. Alessandra Bianchini, Airfields and Pavements Branch (APB), GSL. Drs. Bianchini and Barker prepared this publication under the supervision of Dr. Gary L. Anderton, Chief, APB; Dr. Larry N. Lynch, Chief, Engineering Systems and Materials Division; Dr. William P. Grogan, Deputy Director, GSL; and Dr. David W. Pittman, Director, GSL.

COL Kevin J. Wilson was Commander and Executive Director of ERDC. Dr. J effery P. Holland was Director. 


\section{Unit Conversion Factors}

\begin{tabular}{|c|c|c|}
\hline Multiply & By & To Obtain \\
\hline Feet & 0.3048 & meters \\
\hline Inches & 0.0254 & meters \\
\hline inch-pounds (force) & 0.1129848 & newton meters \\
\hline miles per hour & 0.44704 & meters per second \\
\hline Mils & 0.0254 & millimeters \\
\hline pounds (force) & 4.448222 & newtons \\
\hline pounds (force) per foot & 14.59390 & newtons per meter \\
\hline pounds (force) per inch & 175.1268 & newtons per meter \\
\hline pounds (force) per square foot & 47.88026 & pascals \\
\hline pounds (force) per square inch & 6.894757 & kilopascals \\
\hline pounds (mass) & 0.45359237 & kilograms \\
\hline pounds (mass) per cubic foot & 16.01846 & kilograms per cubic meter \\
\hline pounds (mass) per cubic inch & $2.757990 \mathrm{E}+04$ & kilograms per cubic meter \\
\hline pounds (mass) per square foot & 4.882428 & kilograms per square meter \\
\hline pounds (mass) per square yard & 0.542492 & kilograms per square meter \\
\hline square feet & 0.09290304 & square meters \\
\hline square inches & 6.4516 E-04 & square meters \\
\hline tons (force) & $8,896.443$ & newtons \\
\hline tons (force) per square foot & 95.76052 & kilopascals \\
\hline tons (long) per cubic yard & $1,328.939$ & kilograms per cubic meter \\
\hline tons $(2,000$ pounds, mass $)$ & 907.1847 & kilograms \\
\hline tons ( 2,000 pounds, mass) per square foot & $9,764.856$ & kilograms per square meter \\
\hline
\end{tabular}




\section{Introduction}

In designing flexible pavements for military airfields, minimum thicknesses of surface and base are given in tabular form in the Unified Facilities Criteria (UFC) 3-260-02 based on the aircraft type, traffic area, and base California Bearing Ratio (CBR). These thickness values were empirically established based on pavement performance in full-scale pavement testing using the F-4 as a representative aircraft.

With the development of larger and heavier aircraft, the minimum thickness requirements were adjusted upward based on airfield pavement evaluations. The empirical approach for determining minimum thicknesses was necessary because there was no analytical procedure in place for determining minimum thickness in relation to the type of aircraft and soil characteristics. The U.S. Army Engineer Research and Development Center (ERDC) research team saw a need to provide verification of the empirical approach through the formulation of a rational methodology for determining minimum thicknesses for airfield pavements.

The objective of this paper is to present a rational methodology for determining the required minimum asphalt and base thicknesses for military airfield pavements. In determining the minimum thickness for a given aircraft or Air Force Aircraft Group, the proposed procedure considers aircraft wheel load, tire pressure, load repetitions, and the CBR of both base and subbase layers.

In addition to presenting the methodology for determining layer minimum thicknesses from a structural standpoint, the manuscript briefly presents an examination of the effects of construction methods and materials on minimum thickness. Construction equipment and asphalt material characteristics directly influence the thickness of asphalt layer that can be constructed and its performance when subjected to traffic and the environment.

\section{Background}

Flexible pavements consist of a layered structure of asphalt over compacted granular materials with each layer being capable of sustaining the applied static and dynamic loads and distributing the stresses to the underlying 
layers. The fundamental idea leading to the development of a rational design procedure is that asphalt surface and base courses of high-quality materials have a high resistance to deformation and, therefore, make minimal contribution to permanent deformation due to traffic loading. This is possible when the shear stresses in the granular base and subbase are limited to an acceptable level, which is a function of the layer strength. Thus, the design procedure for determining the required thickness of asphalt surface is based on limiting the shear stress in the granular base layer. Similarly, the procedure for determining the base course required thickness is based on further reducing the stress to an acceptable level at the top of the subbase.

The design procedure uses the CBR as a strength indicator for granular layers and subgrade. Even though a well constructed layer of a 100-CBR material provides high resistance to shear stress, and therefore, to rutting, some minimum thickness of hot-mix asphalt (HMA) is needed to protect this strong base course from the effects of traffic and environment. The importance of granular layers in supporting aircraft load was also acknowledged by Bruce Rodway of Bruce Rodway and Associates (e-mail message to the author). Rodway reported that for many years, a number of pavements at the airport in Sydney, Australia, catering to Boeing 747-type aircraft, consisted of only $50 \mathrm{~mm}$ of asphalt, $300 \mathrm{~mm}$ of fine crushed rock (FCR) resting over sand subgrade with a $15 \mathrm{CBR}$. The wheel path rutting that developed was usually found to be entirely due to deformation of the asphalt layer; the FCR upper surface remained flat or minimally sheared. For reference, the Boeing 747s have 24-ton wheel loads, $1,400 \mathrm{kPa}$, and 200 psi tire pressures.

The good rutting resistance of FCR relative to asphalt was further demonstrated at airports located in hot climates. Rodway mentioned that the problem of persistent hot-weather rutting at aircraft parking positions was solved, or at least reduced, by replacing the existing 150-mm-thick asphalt layer with a FCR layer surfaced with a thin asphalt layer $50 \mathrm{~mm}$ thick. As a further example, Rodway reported past experience with well-constructed FCR pavements surfaced with only 2-coat bitumen-sprayed seal that provided satisfactory service over long periods of use throughout Australia in supporting heavy aircraft such as the B727 (20 tons per wheel, 1,150 kPa, and 170 psi pressure) and the DC9. More recently, these pavements have sustained B737 aircraft. 
In addition to Rodway's contribution about the importance of a highquality granular base layer, Ahlvin (1991) reached similar conclusions from the analysis of the Stockton No. 2 tests (1948). The pavement sections in the Stockton No. 2 full-scale testing program included flexible pavements with different thicknesses of bituminous materials, and base and subbase quality materials. The analysis indicated that at elevated temperatures, the bituminous bound pavement layers were not superior in load distributing capability to excellent quality (100 CBR) base materials. A 100-CBR granular layer is comparable with the FCR layer discussed previously. In conclusion, the basis of the design procedure is determining the layer thicknesses required for protecting granular layers characterized by a given CBR.

The need for an asphalt layer is mainly dictated by operational and structural considerations. From the operational standpoint, the asphalt surface provides a wearing course to prevent material loss or dislodging (e.g., Donovan and Tutumluer 2008, 2009; Tao et al. 2010), a waterproof surface, protection from foreign object damage (FOD), and a durable surface for markings to facilitate aircraft ground operations. From the structural standpoint, high-quality crushed stone bases have shown satisfactory performance under very thin asphalt surfaces. Nevertheless, modern military aircraft with heavily loaded high-pressure tires have proved to be particularly damaging to high-quality bases. In many situations, the military must build airfields where high quality base materials are not locally available. Therefore, the use of the asphalt surface layers is necessary to reduce the stress acting on top of substandard base materials.

Full-scale pavement testing was initially done by the U.S. Army in the 1940s, and additional testing was done in the 1970s. The testing data were used to develop empirical design procedures and evaluate the influence of gear configuration, load, and soil characteristics on pavement performance. More recently, the ERDC executed additional full-scale pavement tests centered specifically on the issue of the minimum thickness (Bell and Mason 2008). The study's objectives were to verify the structural adequacy of the UFC current minimum thickness requirements for the asphalt layer, identify the main failure mechanisms for premature deterioration, and quantify the service life of thin asphalt concrete pavements. Six sections with different layer thicknesses were trafficked with the Heavy Vehicle Simulator (HVS), simulating C-17 and F-15E single-wheel loadings. Tables 1 and 2 summarize the test section and traffic characteristics, respectively. 
Table 1. Section characteristics.

\begin{tabular}{|c|c|c|c|c|c|c|c|}
\hline \multirow[b]{2}{*}{ Section } & \multirow{2}{*}{$\begin{array}{l}\text { Asphalt Layer } \\
\text { Thickness (in.) }\end{array}$} & \multicolumn{2}{|l|}{ Base } & \multicolumn{2}{|c|}{ Subbase (in.) } & \multirow{2}{*}{$\begin{array}{l}\text { Subgrade } \\
\text { CBR }\end{array}$} & \multirow[b]{2}{*}{ Aircraft } \\
\hline & & Thickness (in.) & CBR & Thickness (in.) & CBR & & \\
\hline 1 & 2.5 & 8 & 37.6 & 16 & 46 & 9.8 & C-17 \\
\hline 2 & 3.5 & 7 & 54.2 & 17 & 45.2 & 9.9 & C-17 \\
\hline 3 & 4 & 6.5 & 95.6 & 15 & 47.3 & 9.3 & C-17 \\
\hline 4 & 4 & 6 & 100 & 14.5 & 55 & 9.1 & F-15E \\
\hline 5 & 5 & 6.5 & 51.5 & 13.5 & 56 & 9.4 & C-17 \\
\hline 6 & 5 & 6 & 40 & 12 & 42 & 9.5 & F-15E \\
\hline
\end{tabular}

Table 2. Aircraft load cart characteristics.

\begin{tabular}{|l|l|l|l|}
\hline Aircraft type & Load (lb) & Tire pressure (psi) & P/C \\
\hline C-17 & 37,800 & 142 & 2.41 \\
\hline F-15E & 29,700 & 325 & 4.17 \\
\hline
\end{tabular}

The soil characteristics in Table 1 were determined from CBR field tests prior to trafficking. The pass-to-coverage ratio (P/C) was determined based on a specific traffic pattern programmed for the HVS. Table 3 includes each section's performance characteristics in terms of number of passes and coverages to failure. Failure was defined as 1 in. depth of rut with the depth being measured from a 12-ft straight edge.

Table 3. Sections, number of passes, and coverages to failure.

\begin{tabular}{|l|l|c|c|}
\hline Section & Aircraft & $\begin{array}{l}\text { Measured Number } \\
\text { of Passes to Failure }\end{array}$ & Coverages \\
\hline 1 & C-17 & 234 & 97 \\
\hline 2 & C-17 & 623 & 259 \\
\hline 3 & C-17 & 285 & 118 \\
\hline 4 & F-15E & 42,881 & 10,284 \\
\hline 5 & C-17 & 1,278 & 530 \\
\hline 6 & F-15E & 32,500 & 7,794 \\
\hline
\end{tabular}

The full-scale test data analysis led to a conclusion that the Department of Defense's (DoD) minimum asphalt concrete thickness criteria were acceptable and that the pavement's life would be decreased by at least one half if the minimum asphalt concrete thickness were not met. The data analysis also indicated that an increase of $1 \mathrm{in}$. in the thickness of a thin asphalt concrete surface layer (from $2.5 \mathrm{in}$. to $3.5 \mathrm{in}$.) resulted in an increase of 
about three times the number of passes to failure (based on $1 \mathrm{in}$. of rutting) (Bell and Mason 2008).

Besides structural considerations, the minimum thickness of asphalt layers may also be dictated by construction practices and available materials. For instance, the aggregate size in the asphalt mixture may impact the minimum thickness that can be constructed with that material, while maintaining layer soundness and integrity. The paving equipment and mechanical limitations may also impact minimum thickness that can be achieved. Recommendations on best practices that influence minimum thickness are presented in the manual by Brown et al. (2008). The manual focuses on best practices for construction of HMA mixture and addresses the effect of construction deficiencies on pavement performance.

\section{Objective}

The objective of this paper is to present a methodology for determining minimum thicknesses of asphalt and base layers as related to load and material characteristics, and therefore, to provide an extension of the current UFC criteria of minimum thickness. The methodology is modeled very closely after the CBR-BETA procedure currently under review for introduction into the UFC dedicated to flexible pavement design.

\section{Report content}

The report explains the rational approach for determining asphalt and base layer minimum thicknesses in relation to load and soil characteristics. Chapter 2 contains the rationale about the CBR-BETAmin procedure for computing layer minimum thickness. Chapter 3 offers examples of application of the new proposed methodology. Construction and environmental considerations about the asphalt layer minimum thickness are presented in Chapter 4. The report concludes with Chapter 5, which presents recommendations for the CBR-BETA $A_{\text {min }}$ procedure. 


\section{The CBR-BETA $\min$ Procedure for Computing Minimum Thicknesses}

The development of the CBR-BETAmin procedure for computing minimum thicknesses of surface and base aims to provide a rational method for validating or updating the minimum thickness tables given in the UFC 3-26002. In addition, the procedure is intended to provide a means of developing minimum thicknesses for aircraft and base material characteristics that are not included in the UFC tables. The proposed procedure for computing surface and base minimum thicknesses is based on the BETA parameter as defined by Equation 1. The major differences between the CBR-BETA

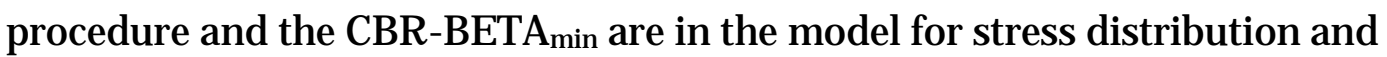
the BETA-coverage relationship used for criteria.

$$
\beta=\frac{\pi \sigma_{z}}{\mathrm{CBR}}
$$

where:

$$
\begin{aligned}
\sigma_{\mathrm{z}} & =\text { stress acting on the subgrade at depth } \mathrm{z} \\
\mathrm{CBR} & =\text { California Bearing Ratio of the subgrade. }
\end{aligned}
$$

\section{Stress distribution model}

The original CBR design procedure, as well as the CBR-BETA design procedure, is based on the concept that, for flexible pavements with a thin asphalt surface relative to the thickness of the granular layers, the stress distribution on the subgrade is unaffected by the quality of the material placed above the subgrade. On the other hand, when considering the stress at the top of base and subbase layers, the presence of asphalt and the quality of unbound granular materials do influence load distribution characteristics, which therefore must be taken into account. Changes in stress distribution with varying layer thickness and material quality is the concept representing the basis of the CBR-BETA $A_{\min }$ design procedure.

The CBR-BETAmin design procedure uses a layered elastic model to compute the vertical stress distribution induced by a single aircraft wheel load, assuming the pavement as a two-layered system composed of an asphalt 
layer over a sub-layer. In a two-layered system, the stress distribution under the loaded area is a function of the upper layer thickness and the moduli ratio between the layers. Based on typical values of asphalt concrete and granular base moduli, a value of 5.0 was selected as ratio between the asphalt layer and the sub-layer moduli. With a fixed moduli ratio, the thickness of asphalt is determined to limit the stress at the top of the base. For a fixed moduli ratio and given asphalt surface thickness, the distribution of stress in the second layer is also fixed. Thus, the base thickness required to protect the subbase can be selected from the stress distribution.

\section{Criteria development for the CBR-BETA min $_{\text {design procedure }}$}

The BETA criteria concept and definition are given by Barker and Gonzalez (2006a, b). The main aspect of any empirical-mechanistic design procedure is the correlation of traffic volume, acting on the pavement, with some computed pavement response. Barker (letter report to the Federal Aviation Administration 2006) developed a formulation relating subgrade strain to aircraft traffic, expressed in terms of coverage, through the layered-elastic analysis of data from full-scale testing. The formulation is contained in Equation 2, expressing allowable strains as a function of coverages.

$$
\log \left(\varepsilon_{\mathrm{z}}\right)=\frac{-2.1582-1.3723 \log (\mathrm{Cov})}{1+0.4115 \log (\operatorname{Cov})}
$$

where:

$$
\begin{aligned}
\varepsilon_{\mathrm{z}} & =\text { vertical strain at depth } \mathrm{z} \\
\mathrm{Cov} & =\text { number of traffic coverages. }
\end{aligned}
$$

By assuming that the Young's modulus can be expressed as function of CBR as in Equation 3,

$$
\mathrm{E}_{\mathrm{s}}=1500 \mathrm{CBR}
$$

BETA can be defined in terms of vertical strain, as in Equation 4 .

$$
\beta=\pi \varepsilon_{\mathrm{z}} 1500
$$


A relationship between BETA and coverages approximating the relationship between strain and coverages can be developed using Equation 1 and Equation 3 and is given in Equation 5.

$$
\log (\beta)=\frac{1.477+0.1079 \log (\mathrm{Cov})}{1+0.377 \log (\mathrm{Cov})}
$$

Figure 1 shows the CBR-BETA criteria curve, which was developed using a stress distribution model that does not consider the effect of material quality on the stress distribution (upper curve), and it shows the criteria curve from Equation 5 that does consider the effect of material quality. The shape of the function chart from Equation 5 reflects the trends noted in the test data but is downshifted from the CBR-BETA curve. This is because Equation 5 was developed through a layered-elastic model, which accounted for the material quality at each layer.

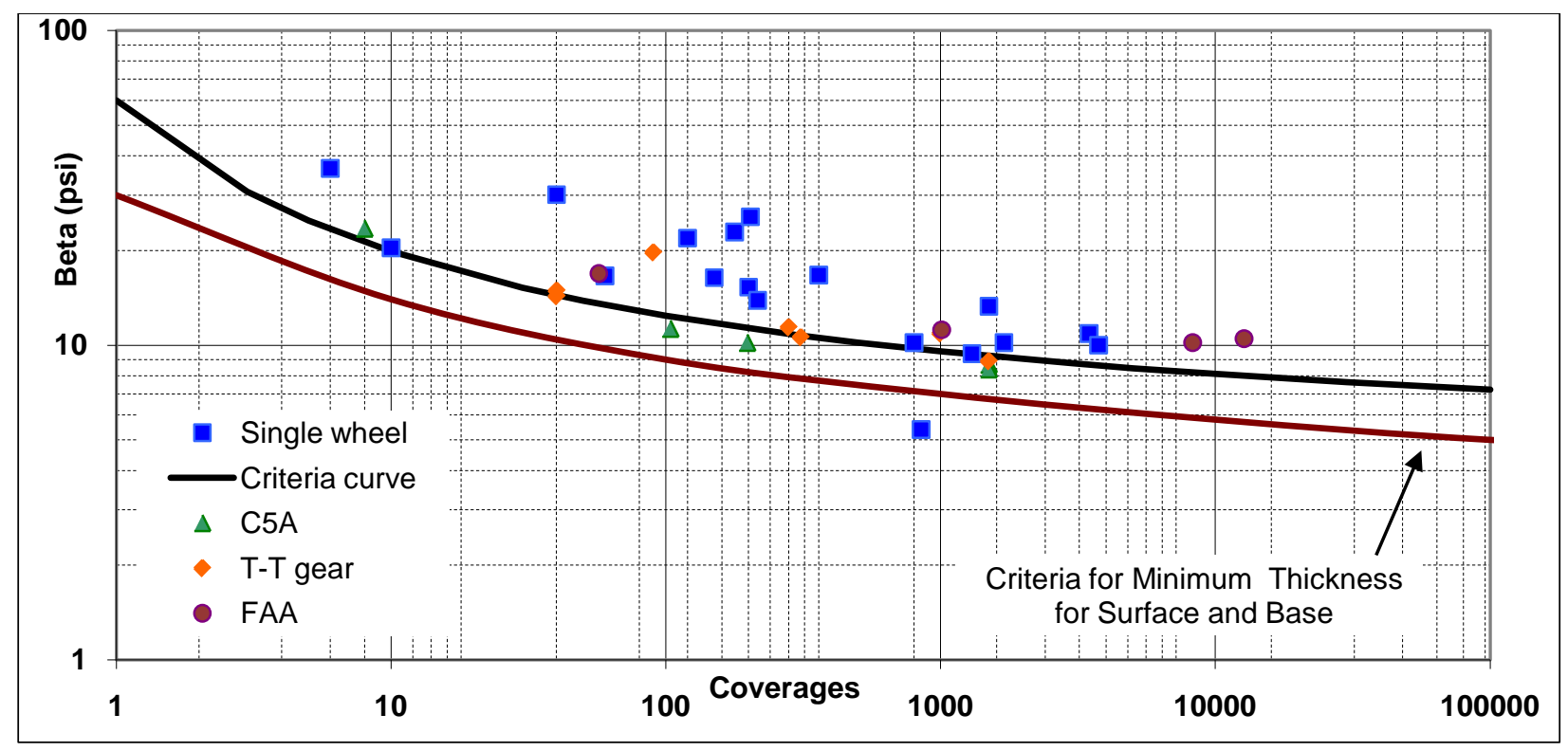

Figure 1. Criteria for minimum thickness.

Using these criteria, asphalt and base minimum thicknesses were computed and compared to the minimum thicknesses tabulated in the UFC 3260-02. The computed values were in acceptable agreement with the tabulated values. The finding recommended adopting of the criteria as in Equation 5 to compute minimum thickness. However, additional studies are recommended to finalize the CBR-BETA $\mathrm{min}_{\text {in }}$ as the procedure for determining the minimum thicknesses for airfield pavements. 


\section{Methodology for minimum thickness}

The development of the CBR-BETAmin approach for determining the minimum thickness of asphalt and base layers considered only the load-related aspects of this problem. The load configuration to determine minimum thickness included exclusively one tire. The use of a single tire was justified by the fact that at limited depths, the contribution of stress due to adjacent tires is insignificant. A two-layered system represents the typical pavement structure of an asphalt surface over a granular foundation. The ratio of the asphalt modulus over the modulus of the granular foundation was set equal to 5. For both layers, the Poisson's ratio was taken equal to 0.5 , which implies no volume deformation under load. Using the traffic volume in terms of coverages, the design value of BETA is determined from either the criteria curve given in Figure 1, or the function in Equation 3. In relation to base and subbase CBR values, the allowable stress for each layer is computed from the basic definition of BETA in Equation 1. Once the allowable stresses for base and subbase are determined, a layered elastic model allows computing the asphalt and base layers thicknesses required to limit the stress at the top of the base and subbase.

\section{Development of graphical solution}

The development of a graphical solution for the CBR-BETAmin procedure is possible because of the simplified stress distribution model and by assuming a constant contact area for all loaded tires. With the assumption of a constant contact area, the stress has a linear relation with contact pressure, which allows developing the procedure to consider different tire pressures. A tire pressure of $300 \mathrm{psi}$ and a contact area radius of $5 \mathrm{in}$. were set as reference values. The layered-elastic computer program, BISAR, was used to compute at different depths the stresses generated by the applied load. Each depth was normalized with respect to the reference radius of the contact area. The computed vertical stresses were then employed to calculate the value of BETA by Equation 1 with the value of CBR set to 100. In this way, it is possible to express BETA as a function of the ratio of the asphalt thickness and radius of the loaded area. Figure 2 shows the relationship between the thickness-radius ratio and BETA for the applied stress of $300 \mathrm{psi}$ and 100 CBR base. As design criteria, BETA is a function of the traffic volume expressed in terms of coverage (Equation 5). Therefore, traffic volume allows computing the value of BETA to be used in determining the required thickness of asphalt and base. 


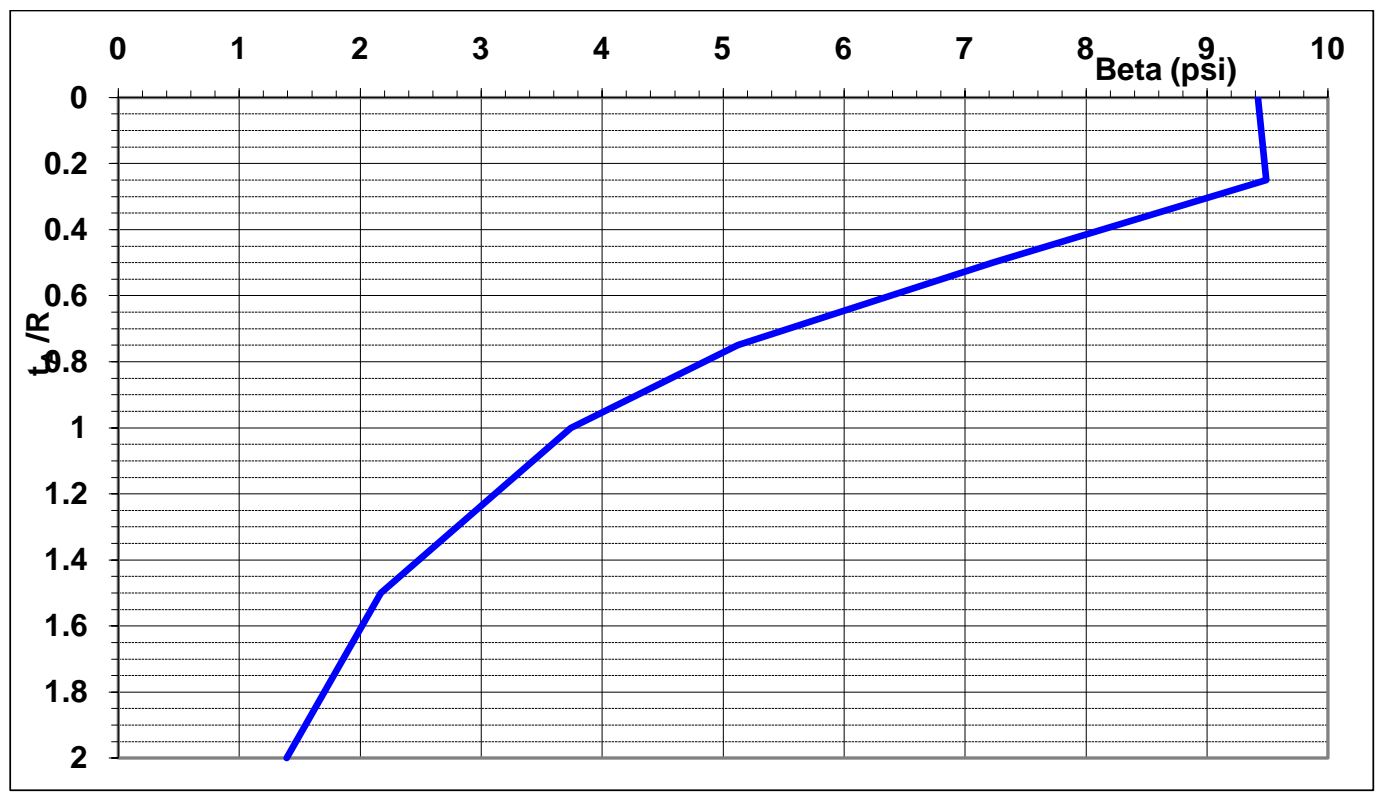

Figure 2. Design chart for asphalt layer thickness.

Since there is a linear relationship between BETA, tire pressure, and CBR, the BETA computed for the reference tire and CBR can be converted to a BETA associated to different tire pressure and CBR. When the thickness value determines a BETA that satisfies the design criteria, the design BETA is equal to the computed BETA; therefore, the adjustment for different tire pressure and CBR can be made to the design BETA rather than to the computed BETA. The adjusted BETA is computed for different values of the applied stress and base CBR through Equation 6.

$$
\beta_{\text {adj }}=\beta_{\text {des }} \frac{\text { CBR }}{100} \frac{300}{p}
$$

where:

$$
\begin{aligned}
\beta_{\text {adj }} & =\text { adjusted BETA } \\
\beta_{\text {des }} & =\text { design BETA determined from traffic volume } \\
\text { CBR } & =\text { base soil strength } \\
\mathrm{p} & =\text { tire pressure }
\end{aligned}
$$

The adjusted BETA is then used in Figure 2 to determine the asphalt layer thickness to protect the base.

The approach to determining the base thickness required to protect the subbase is similar to the approach used in determining the asphalt 
minimum thickness. The stress distribution in the granular base and subbase layers determines the base thickness needed to protect the subbase. Because the stress distribution in the granular layers is influenced by the asphalt thickness, the procedure to compute base layer thickness includes the use of parametric curves based on the ratio $t_{A} / R$, where $R$ is the radius of the contact area. The parametric curves expresses BETA as function of the total pavement thickness T. Figures 3 to 8 provide the stress distributions for various values of asphalt thickness-radius ratio $t_{\mathrm{A}} / \mathrm{R}$ from 0.75 to 2.0. For a particular loading and subbase CBR, the adjusted BETA is entered in the appropriate distribution curve (Figures 3 through 8 ) to determine the total thickness-radius ratio to limit the stress at the top of the subbase. From this ratio, the required thickness of the base can be computed. In summary, computation of the granular base thickness required to protect the subbase consists of the following steps:

1. Calculate the ratio $t_{A} / R$ to select the appropriate curve.

2. Calculate the design BETA using Equation 3, or Figure 1.

3. Calculate the adjusted BETA using Equation 6.

4. Input the adjusted BETA in the correct parametric curve to identify the ratio $T / R$ where $T$ is the pavement thickness above the subbase.

5. Subtract $t_{A}$ from $T$ to compute the base layer thickness.

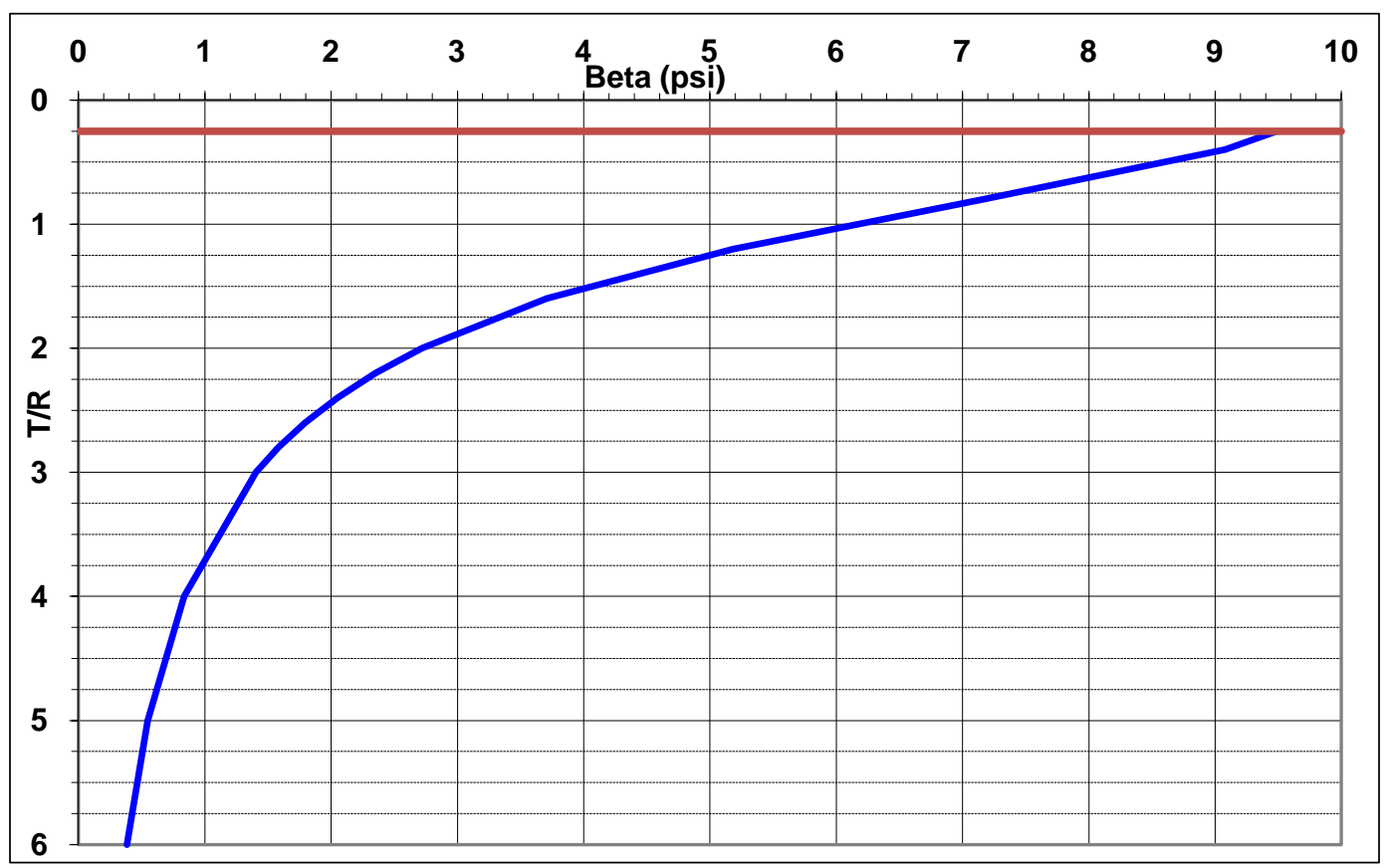

Figure 3. Design chart for base layer $\left(t_{A} / R=0.25\right)$. 


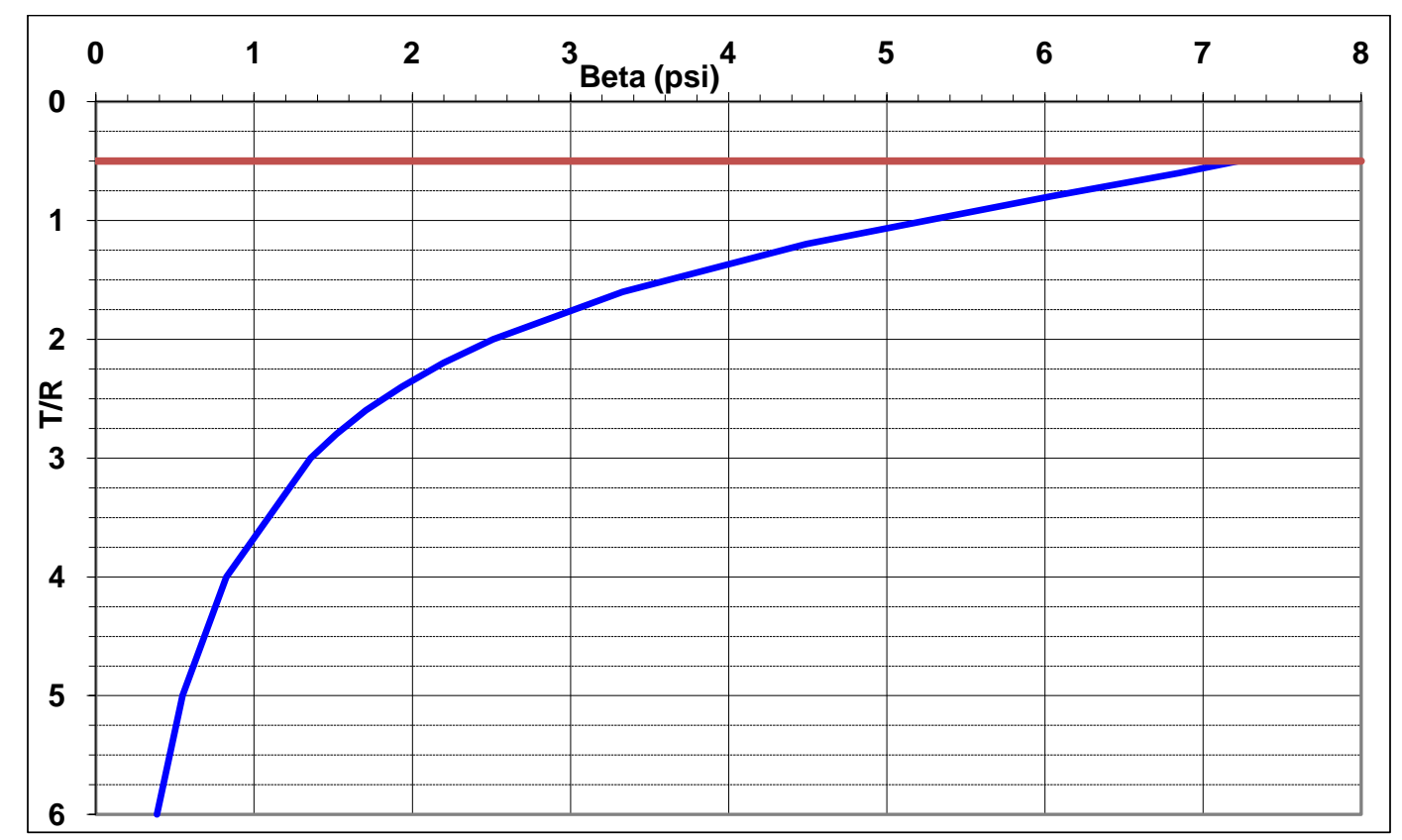

Figure 4. Design chart for base layer $\left(t_{A} / R=0.5\right)$.

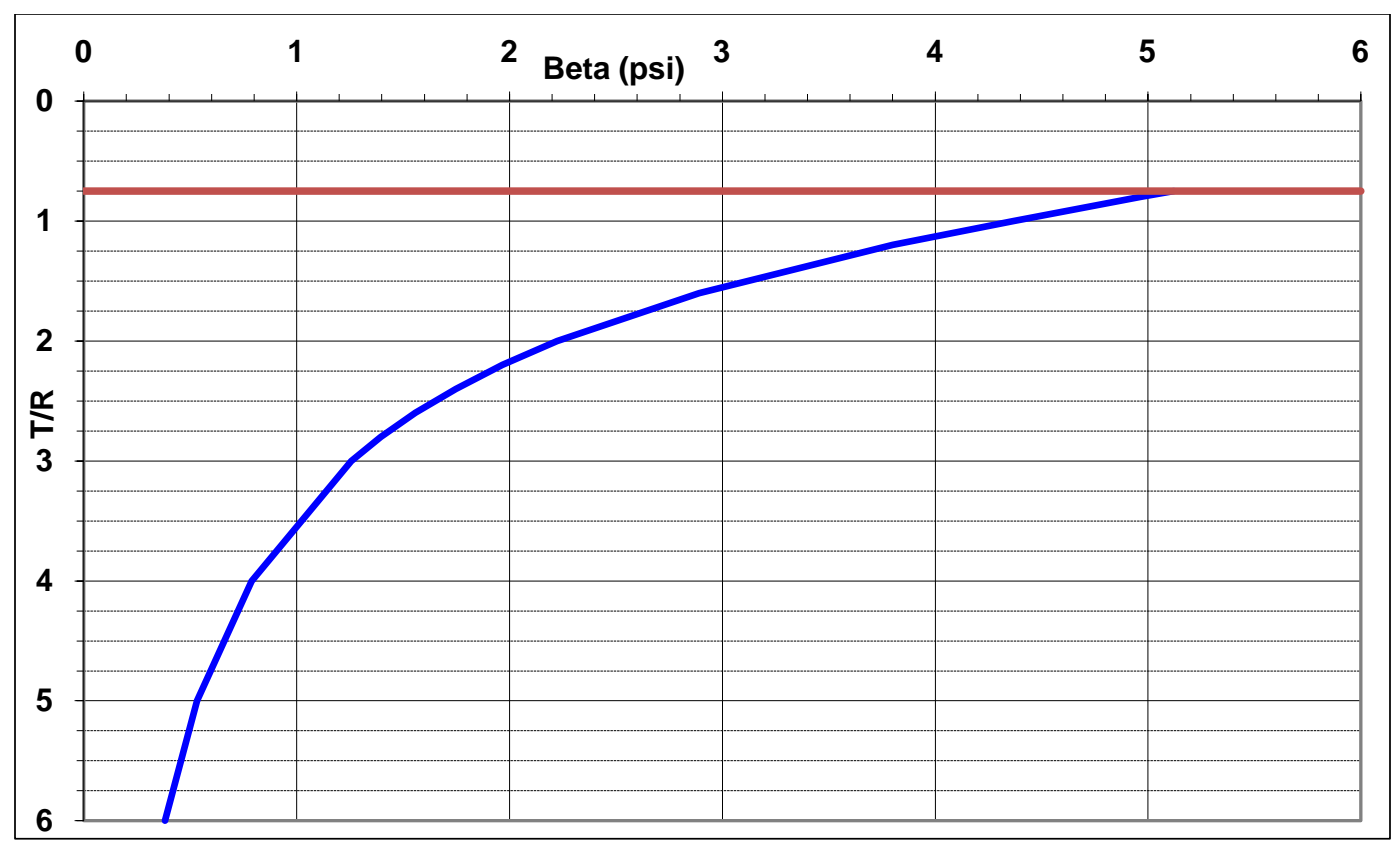

Figure 5. Design chart for base layer $\left(t_{A} / R=0.75\right)$. 


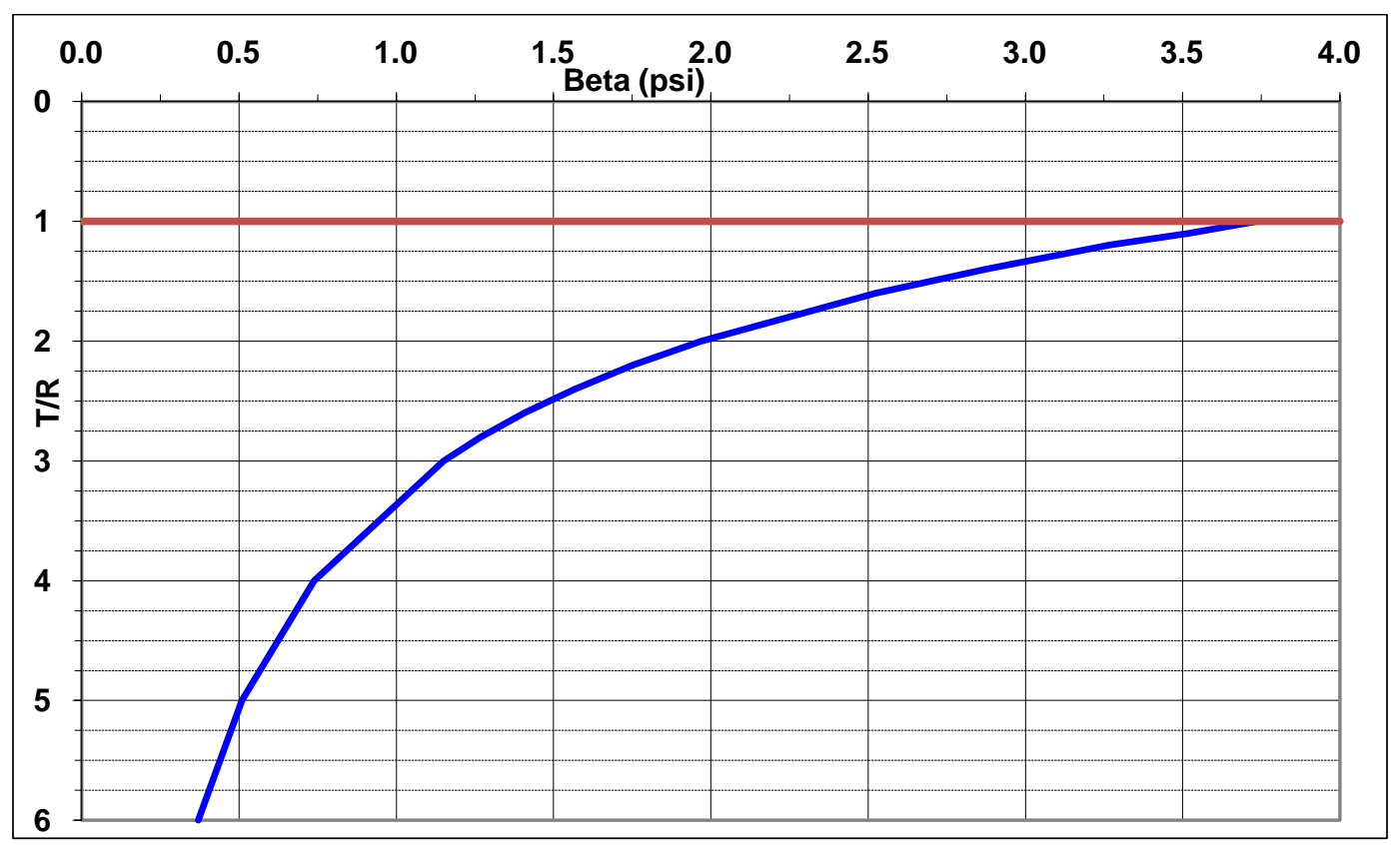

Figure 6. Design chart for base layer $\left(t_{A} / R=1\right)$.

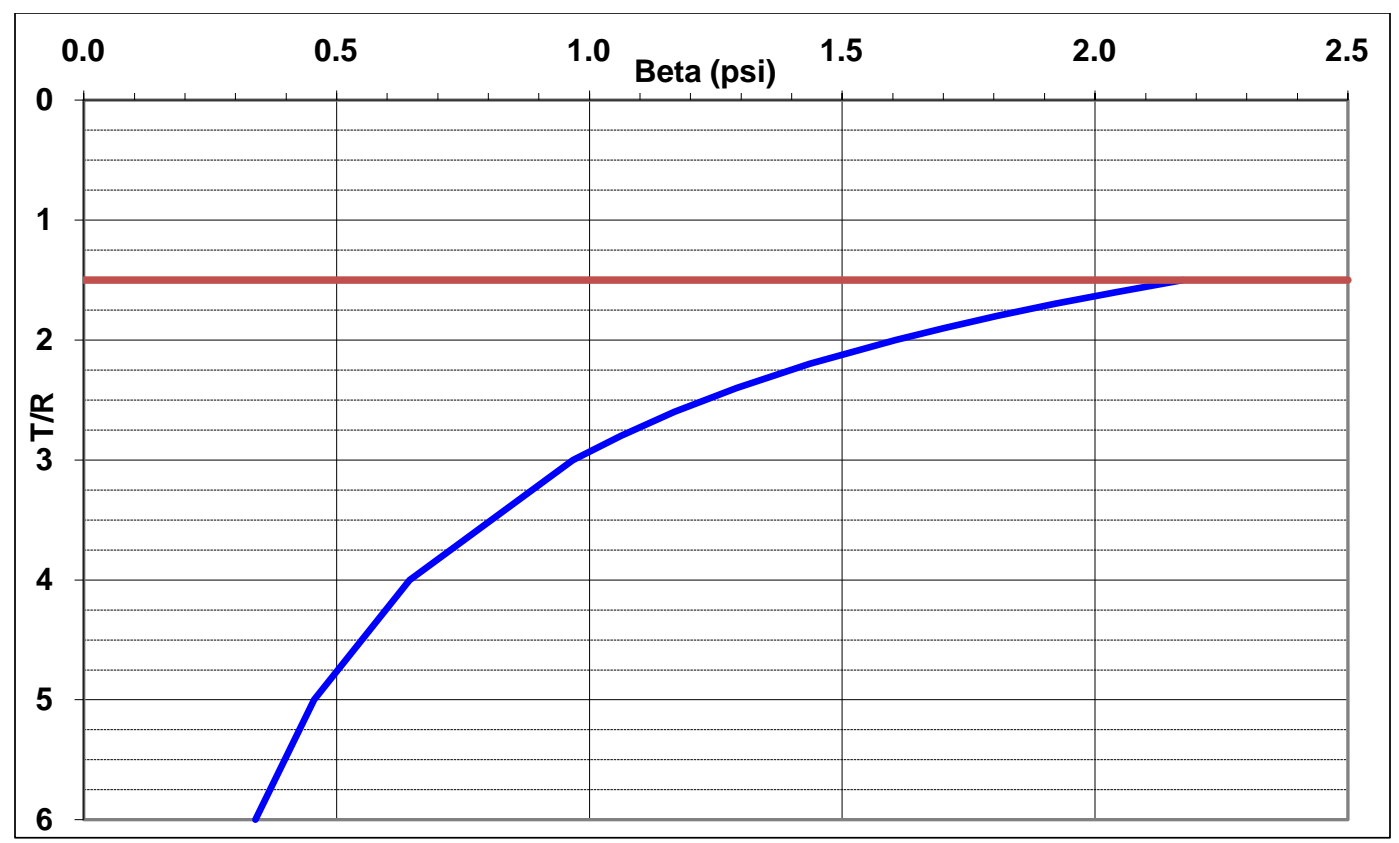

Figure 7. Design chart for base layer $\left(t_{A} / R=1.5\right)$. 


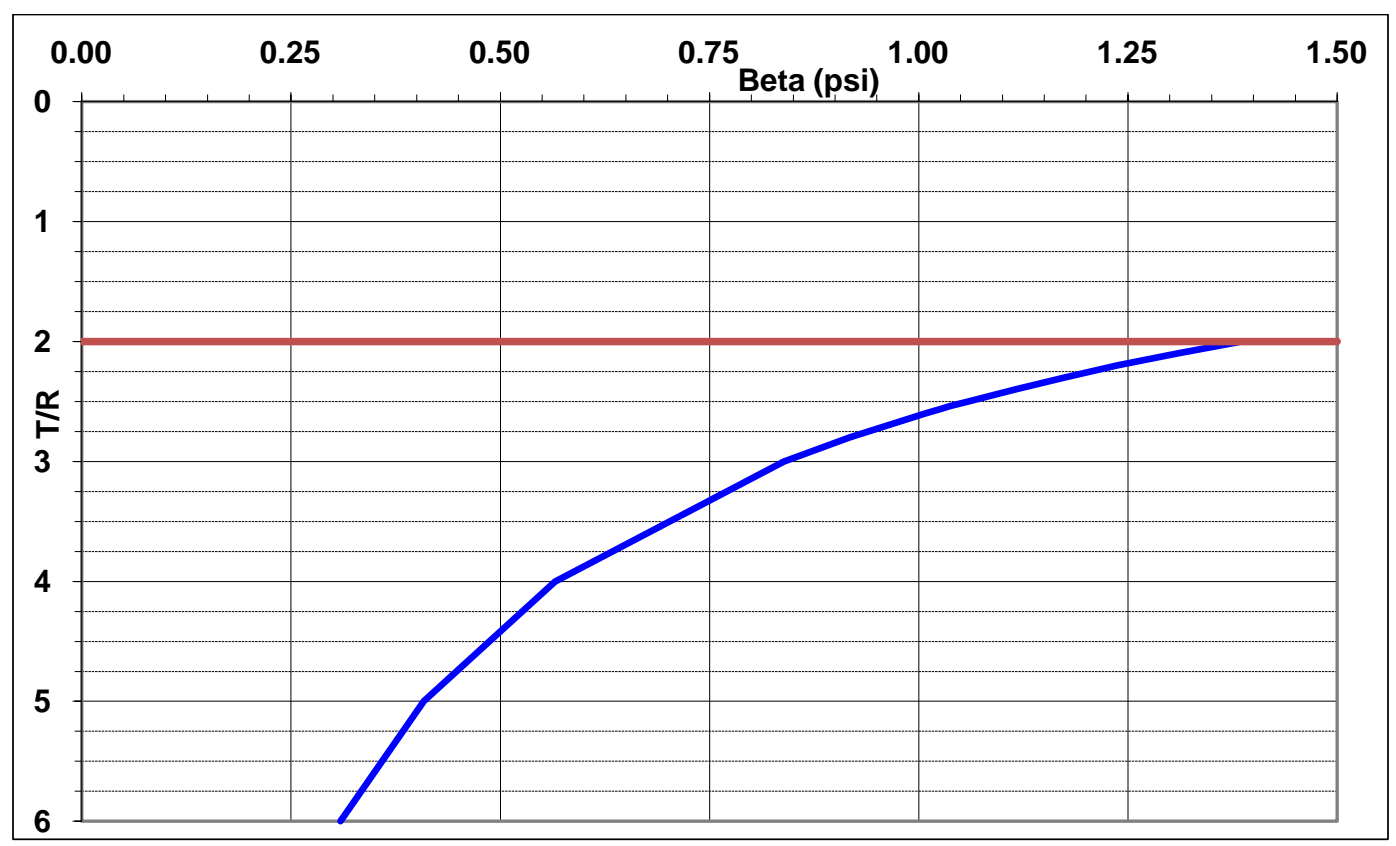

Figure 8. Design chart for base layer $\left(t_{A} / R=2\right)$.

\section{Software}

The basic CBR-BETA $\mathrm{Am}_{\min }$ procedure to determine minimum thickness was also included in a dedicated software package named PVT. The computer program uses the same methodology as the graphical procedure, although it differs from the graphical procedure for two aspects. One of the differences is in the software used to compute vertical stresses. The computer program uses the layered-elastic software J ULEA instead of BISAR. The other difference between graphical procedure and computer solution is that all tires flagged for layered-elastic analysis are included in the stress computations. These differences between the graphical and computer solutions are minimal, and the two methods produce virtually the same results.

In calculating minimum thickness using PVT, the efforts are reduced to a list of inputs that includes: selection of the reference aircraft, traffic volume, and traffic area, base and subgrade CBR values, and asphalt surface and base minimum thicknesses, based on constructability. The latter two inputs are usually tabulated values. 


\section{Calculations of Minimum Thickness - Examples}

The examples illustrate the graphical procedure in determining pavement layer minimum thickness. A 45,000-lb load is applied to a single tire with pressure of 300 psi in Example 1 and 185 psi in Example 2. The computer solution provides a comparison with the current pavement thickness requirements contained in the UFC 3-260-02.

\section{Example 1}

The first design example is for an aircraft having a single-wheel loading of $45,000 \mathrm{lb}$ with $300 \mathrm{psi}$ as tire contact pressure. The minimum thicknesses of the asphalt layer will be determined for CBR values of base material of 100, 80, and 50, and traffic volumes of 1,000; 10,000; and 100,000 coverages. In addition, the required thicknesses of a $100 \mathrm{CBR}$ base material will be determined for subbases characterized by CBR of 50 and 30 .

The tire contact area is calculated with the formula

$$
A=\frac{P}{p}
$$

where:

$$
\begin{aligned}
& \mathrm{P}=\text { aircraft load applied to the specific tire } \\
& \mathrm{p}=\text { tire pressure. }
\end{aligned}
$$

In this case, $\mathrm{A}$ is equal to $150 \mathrm{in} .^{2}$ with a radius of $6.9 \mathrm{in}$., assuming a circular contact area. The design values of BETA, obtained from Figure 1, or calculated using Equation 5, are 7.1, 5.8, and 5.0 for 1,000; 10,000; and 100,000 coverages, respectively. For 100-CBR soil, the adjusted BETA values coincide with the BETA computed from Equation 3. Inputting the BETA values in the chart of Figure 2 provides the T/ $R$ values of $0.53,0.66$, and 0.77 for 1,000; 10,000; and 100,000, respectively. Since the radius $R$ of the contact area is $6.9 \mathrm{in}$., the thicknesses of asphalt layer required over the $100-\mathrm{CBR}$ base are $3.7 \mathrm{in} ., 4.6 \mathrm{in}$. and $5.3 \mathrm{in}$. 
For the 80-CBR base, the initial BETA values are calculated through Equation 5, and their adjusted values are computed by Equation 6 and are equal to 5.6, 4.6, and 4.0 for 1,000; 10,000; and 100,000 coverages, respectively. From Figure 2, the thickness-to-radius ratio values are 0.7, 0.84, and 0.94 . The required asphalt layer thicknesses that result are $4.8 \mathrm{in} ., 5.8 \mathrm{in}$. , and $6.5 \mathrm{in}$. for the design levels of coverages.

Following the same procedure for the 50-CBR base, the required asphalt layer thicknesses are 7.4 in., 8.8 in., and $9.7 \mathrm{in}$. for coverages of 1,000; 10,000; and 100,000, respectively. Table 4 summarizes the values computed for base CBR of 100, 80, and 50.

Table 4. Asphalt thickness data for Example 1.

\begin{tabular}{|r|l|l|l|l|l|l|l|l|l|l|}
\hline & & \multicolumn{3}{|c|}{100 CBR Base } & \multicolumn{3}{c|}{80 CBR Base } & \multicolumn{3}{c|}{50 CBR Base } \\
\cline { 2 - 12 } Coverages & BETA & $\begin{array}{l}\text { Adjusted } \\
\text { BETA }\end{array}$ & $\mathrm{t} / \mathrm{r}$ & $\begin{array}{l}\text { Thickness } \\
\text { (in.) }\end{array}$ & $\begin{array}{l}\text { Adjusted } \\
\text { BETA }\end{array}$ & $\begin{array}{l}\text { Thickness } \\
\text { (in.) }\end{array}$ & $\begin{array}{l}\text { Adjusted } \\
\text { BETA }\end{array}$ & $\begin{array}{l}\text { Thickness } \\
\text { t/r } \\
\text { (in.) }\end{array}$ \\
\hline 1,000 & 7.1 & 7.1 & 0.53 & 3.7 & 5.6 & 0.70 & 4.8 & 3.5 & 1.07 & 7.4 \\
\hline 10,000 & 5.8 & 5.8 & 0.66 & 4.6 & 4.6 & 0.84 & 5.8 & 2.9 & 1.28 & 8.8 \\
\hline 100,000 & 5.0 & 5.0 & 0.77 & 5.3 & 4.6 & 0.94 & 6.5 & 2.5 & 1.40 & 9.7 \\
\hline
\end{tabular}

Once the asphalt minimum thickness is determined, the base minimum thickness can be computed. This example considers the case of determining the thickness of a 100-CBR base over a 50-CBR subbase. For the appropriate traffic level and base CBR, Table 4 provides the asphalt minimum thicknesses and the ratio $t_{A} / r$. The next step is to determine the total value of thickness T needed to protect the subbase. The BETA values, computed by Equation 5 and adjusted through Equation 6, are 3.5, 2.9, and 2.5 for coverage levels of 1,000; 10,000; and 100,000, respectively. For 1,000 coverages, the surface thickness-radius ratio $t_{A} / R$ is 0.53 (Table 4 ). Since the thickness-radius ratio is close to 0.5, the design chart of Figure 4 is used to determine the total thickness-radius ratio T/R. For the adjusted BETA of 3.5, the ratio T/ $R$ is 1.5; and the total thickness $T$ above the subbase is 10.4 in. The surface thickness, previously calculated, was 3.7 in.; therefore, the required thickness of 100-CBR base is $6.7 \mathrm{in}$.

For 10,000 coverages, Table 4 provides the surface thickness-radius ratio $t_{A} / R$ of 0.66 . Since the ratio is between 0.5 (Figure 4 ) and 0.75 (Figure 5), the value of 1.7 for the ratio $T / R$ is obtained by interpolation of the values from Figures 4 and 5. Interpolation of the ratio and subsequent multiplication by the contact area radius $\mathrm{R}$ result in the total thickness $\mathrm{T}$ of $11.7 \mathrm{in}$. 
above the subbase and base thickness of 7.1 in. Similarly for 100,000 coverages, the base required thickness is 7.1 in.

Similar procedure for a 30-CBR subbase leads to the required base thicknesses of $11.5 \mathrm{in} ., 12.7 \mathrm{in}$., and $12.6 \mathrm{in}$. for 1,000 coverages; 10,000 coverages; and 100,000 coverages, respectively. Table 5 summarizes the example computations.

Table 5. Base thickness data for Example 1.

\begin{tabular}{|c|c|c|c|c|c|c|c|c|c|}
\hline \multirow[b]{2}{*}{ Coverages } & \multirow[b]{2}{*}{ BETA } & \multicolumn{4}{|c|}{50 CBR Base } & \multicolumn{4}{|c|}{30 CBR Base } \\
\hline & & $\begin{array}{l}\text { Adjusted } \\
\text { BETA }\end{array}$ & $t / r$ & \begin{tabular}{|l} 
Total \\
Thickness \\
(in.)
\end{tabular} & $\begin{array}{l}\text { Base } \\
\text { Thickness }\end{array}$ & $\begin{array}{l}\text { Adjusted } \\
\text { BETA }\end{array}$ & $t / r$ & \begin{tabular}{|l} 
Total \\
Thickness \\
(in.)
\end{tabular} & \begin{tabular}{|l} 
Base \\
Thickness
\end{tabular} \\
\hline 1,000 & 7.0 & 3.5 & 1.5 & 10.4 & 6.7 & 2.1 & 2.2 & 15.2 & 11.5 \\
\hline 10,000 & 5.8 & 2.9 & 1.7 & 11.7 & 7.1 & 1.74 & 2.5 & 17.3 & 12.7 \\
\hline 100,000 & 5.0 & 2.5 & 1.8 & 12.4 & 7.1 & 1.5 & 2.6 & 17.9 & 12.6 \\
\hline
\end{tabular}

\section{Example 2}

The second example includes the same tire load of Example 1(45,000 lb) but with a tire pressure of $185 \mathrm{psi}$. The contact area is $243.24 \mathrm{in}^{2}$ with a radius of 8.8 in. Tables 6 and 7 include data of asphalt surface and base minimum thicknesses obtained via the procedure as in Example 1.

From Table 6, it is possible to note that no asphalt surface is required over the 100-CBR base for 1,000 coverages. If based exclusively on load considerations, there would be no need for an asphalt layer over a base characterized by a CBR of 100 . Nevertheless for operational purposes, a minimum thickness of asphalt is needed to provide an adequate wearing surface and protection of aircraft from FOD. In this case, the asphalt layer minimum thickness is established on other considerations such as the asphalt mixture nominal maximum aggregate size (NMAS) and construction feasibility.

\section{Considerations}

The asphalt layer thickness, whether based on structural or other considerations, is used in determining the base minimum thickness needed to protect the subbase. For instance, assuming that the asphalt layer minimum thickness is $2 \mathrm{in}$. and the contact area radius $\mathrm{R}$ is $6.9 \mathrm{in}$., the 0.25-thickness-radius ratio curve will then provide the total thickness $\mathrm{T}$ required above the subbase. 
Table 6. Asphalt thickness data for Example 2.

\begin{tabular}{|c|l|l|l|l|l|l|l|l|l|l|}
\hline \multirow{2}{*}{ Coverages } & \multirow{2}{*}{} & \multicolumn{3}{|c|}{100 CBR Base } & \multicolumn{3}{c|}{80 CBR Base } & \multicolumn{3}{c|}{50 CBR Base } \\
\cline { 2 - 12 } & $\begin{array}{l}\text { BETjusted } \\
\text { BETA }\end{array}$ & $\mathrm{t} / \mathrm{r}$ & $\begin{array}{l}\text { Thicknes } \\
\mathrm{s} \text { (in.) }\end{array}$ & $\begin{array}{l}\text { Adjusted } \\
\text { BETA }\end{array}$ & $\mathrm{t} / \mathrm{r}$ & $\begin{array}{l}\text { Thicknes } \\
\mathbf{s} \text { (in.) }\end{array}$ & $\begin{array}{l}\text { Adjusted } \\
\text { BETA }\end{array}$ & $\begin{array}{l}\text { Thicknes } \\
\mathrm{s} \text { (in.) }\end{array}$ \\
\hline 1,000 & 7.0 & 11.4 & 0 & 0 & 9.1 & $\begin{array}{l}0.3 \\
0\end{array}$ & 2.6 & 5.7 & $\begin{array}{l}0.6 \\
8\end{array}$ & 6.0 \\
\hline 10,000 & 5.8 & 9.4 & $\begin{array}{l}0.2 \\
4\end{array}$ & 2.1 & 7.5 & $\begin{array}{l}0.4 \\
8\end{array}$ & 4.2 & 4.7 & $\begin{array}{l}0.8 \\
4\end{array}$ & 7.4 \\
\hline 100,000 & 5.0 & 8.1 & $\begin{array}{l}0.4 \\
0\end{array}$ & 3.5 & 6.5 & $\begin{array}{l}0.5 \\
8\end{array}$ & 5.1 & 4.0 & $\begin{array}{l}0.9 \\
6\end{array}$ & 8.5 \\
\hline
\end{tabular}

Table 7. Base thickness data for Example 2.

\begin{tabular}{|l|l|l|l|l|l|l|l|l|l|}
\hline \multirow{2}{*}{ Coverages } & \multirow{2}{*}{} & \multicolumn{3}{|c|}{50 CBR Base } & \multicolumn{3}{c|}{30 CBR Base } \\
\cline { 2 - 10 } & BETA & $\begin{array}{l}\text { Adjusted } \\
\text { BETA }\end{array}$ & $\begin{array}{l}\text { Total } \\
\text { t/rickness } \\
\text { (in.) }\end{array}$ & $\begin{array}{l}\text { Base } \\
\text { Thickness }\end{array}$ & $\begin{array}{l}\text { Adjusted } \\
\text { BETA }\end{array}$ & $\begin{array}{l}\text { Total } \\
\text { Thickness } \\
\text { (in.) }\end{array}$ & $\begin{array}{l}\text { Base } \\
\text { Thickness }\end{array}$ \\
\hline 1,000 & 7.0 & 5.7 & 1.1 & 9.8 & $7.6^{*}$ & 3.4 & 1.7 & 15.0 & 12.8 \\
\hline 10,000 & 5.8 & 4.7 & 1.3 & 11.4 & $9.2 *$ & 2.8 & 2.0 & 17.6 & 15.4 \\
\hline 100,000 & 5.0 & 4.0 & 1.4 & 12.3 & 8.8 & 2.4 & 2.0 & 18.5 & 15.0 \\
\hline
\end{tabular}

The two examples provide elements to make a preliminary judgment about the appropriateness of the procedure for determining asphalt and base layer minimum thickness. The examples show that for the same loading, higher tire pressure (300 psi) requires thicker asphalt layer than lower tire pressure ( $185 \mathrm{psi}$ ) but the required base thickness is about the same for both cases and does not have sensitive changes in relation to tire pressure. The required asphalt layer thickness increases with increasing traffic volume and with decreasing base CBR. For the given tire load (45,000 lb) and subbase strength, the required base thickness slightly increases for increasing traffic volume. For both loadings, the total thickness required above the subbase, and therefore, the base thickness, are very sensitive to strength of the subbase.

The CBR-BETA $A_{\min }$ approach provides a consistent methodology to evaluate minimum thickness for all aircraft, traffic volumes, and pavement design parameters. For the purpose of illustration, the CBR-BETAmin procedure was used to compute minimum thickness for a heavy airfield pavement and traffic area A, which is characterized by channelized traffic type. The software PVT was used in the analysis rather than the graphical procedure. The computer analysis included the three aircraft F-15E, C-17, and B-52 at their maximum load. Table 8 includes the aircraft 
characteristics. The results about minimum thickness computation are summarized in Table 9, which also includes comparison with the UFC 3260-02 thickness requirements.

Table 8. Aircraft characteristics.

\begin{tabular}{|l|l|l|l|l|}
\hline \multicolumn{1}{|c|}{ Aircraft } & \multicolumn{1}{|c|}{ Load per tire (lb) } & \multicolumn{1}{|c|}{ Tire pressure (psi) } & \multicolumn{1}{c|}{ Contact area (in. ${ }^{2}$ ) } & Radius (in) \\
\hline B-52 & 62,400 & 235 & 266 & 9.2 \\
\hline F-15E & 35,000 & 300 & 117 & 6.1 \\
\hline C-17 & 45,000 & 142 & 317 & 10.3 \\
\hline
\end{tabular}

Table 9. Comparison of UFC minimums with computed minimums.

\begin{tabular}{|l|c|l|l|l|l|l|}
\hline \multirow{4}{*}{ Aircraft } & \multirow{2}{*}{} & \multirow{2}{*}{ Base CBR } & Subbase CBR & Surface Thickness & \multicolumn{2}{c|}{ Base Thickness } \\
\cline { 3 - 7 } & 100 & 50 & UFC & Computed & UFC & Computed \\
\hline \multirow{4}{*}{ B-52 } & 80 & 50 & 5 & 5.16 & 10 & 9.6 \\
\cline { 2 - 7 } & 50 & 30 & 6 & 6.72 & 9 & 6.7 \\
\hline \multirow{4}{*}{ F-15E } & 100 & 50 & NA & 10.59 & NA & 7.9 \\
\cline { 2 - 7 } & 80 & 50 & NA & 4.00 & NA & 6.22 \\
\hline \multirow{4}{*}{ C-17 } & 50 & 30 & NA & 5.03 & NA & 4.31 \\
\cline { 2 - 7 } & 100 & 50 & NA & 7.53 & NA & 4.88 \\
\cline { 2 - 7 } & 80 & 50 & NA & 4.00 & NA & 7.05 \\
\cline { 2 - 7 } & 50 & 30 & NA & 4.00 & NA & 7.05 \\
\hline
\end{tabular}

The comparison of the BETA-approach results with the UFC tabulated values shows the importance of considering tire pressure of the specific aircraft and CBR of the granular layer within the case under study. For the aircraft B-52, UFC and CBR-BETAmin procedure solutions, rounded up to the nearest inch, converge to the same value when the base and subbase are characterized by CBR values of 100 and 50, respectively. However, the 80-CBR base and 50-CBR subbase determine an asphalt layer $1 \mathrm{in}$. thicker than as recommended in the UFC, although the base thickness is reduced by 2 in. Reducing the subbase CBR does not affect the required asphalt thickness but it does influence the base thickness by increasing it.

The CBR-BETA $A_{\min }$ approach offers a consistent methodology for determining minimum thickness that can be applied to evaluate each scenario in terms of tire pressure and granular layer CBR. For this reason, it can be used as a supplement to the current UFC 12-123-11 by providing some guidance for minimum thickness related to specific aircraft type and soil CBR values. 


\section{Minimum Asphalt Thickness Based on Construction and Environmental}

The layer minimum thickness is not exclusively related to flexible pavement structural requirements or operational needs; it also depends on construction practices and environmental conditions of the site. The following section provides guidance on the need for a minimum thickness of HMA layer from construction and environmental standpoints.

\section{Minimum thickness and construction practice}

During construction, there are several factors, which may affect HMA minimum thickness. Studies (Brown et al. 2004; 2005) have shown that the minimum thickness of a layer should be at least three times the nominal maximum aggregate size (NMAS) and at least four times the nominal maximum size when coarse graded mixtures are used. This generally equates to approximately two to three times when comparing the minimum thickness to the maximum aggregate size.

The guide specification for airfields UFGS 32-12-15 provides the option to use one of three different gradations. Gradation No. 1 is characterized by 1-in. maximum size aggregate; gradation No. 2 has 3/4-in. maximum size aggregate, whereas gradation No. 3 has 1/2-in. maximum size aggregate. Therefore, if a 1.5-in. layer is to be constructed, only two of the three gradation options can be used, assuming that the gradation is fine graded. If the gradation is considered to be a coarse graded mixture, then only the 1/2-in. maximum size gradation can be used.

Another factor to consider is the variation in thickness resulting from the construction process. The thickness variability during construction may be significant, depending on the smoothness of the surface being overlain. This significant variability in thickness will result in a need for a thicker layer of asphalt to ensure that the entire pavement surface, including the thinner sections, meets the thickness to maximum aggregate size requirements.

The issue of thickness variability is more evident during pavement overlay construction. When existing pavements are overlaid, the overlay thickness likely varies more than the thickness of a layer in a new pavement. So, for 
the gradations recommended in the guide specification, the minimum layer thickness of HMA should be greater than $1.5 \mathrm{in}$. Standard practice recommends at least 2 in. of thickness to ensure adequate thickness throughout the area of pavement being placed.

Within the construction process and especially during layer compaction, air and mix temperature represent important factors during construction of thin HMA layers (Brown et al. 2004; 2005). Thin HMA layers tend to cool faster, making it much more difficult to compact. Experience has shown that layers thinner than $1.5 \mathrm{in}$. cool too quickly and are very difficult to compact to meet specification requirements. This is especially true when paving in cooler temperatures with significant wind. Placing thicker mixtures slows the material cooling rate, allowing adequate compaction.

Besides the material temperature issue, layer thickness comparable to maximum aggregate size in the mixture may induce mixture pulling and tearing during placement. When the section gets too thin, pulling and tearing is likely to occur, which can result in a nonuniform and open mat, and in a porous mixture, which tends to be permeable to air and water. In relation to the allowed aggregate gradation, a minimum thickness of 2 in. is recommended in order to prevent excessive mixture pulling and tearing.

\section{Minimum thickness and environmental issues}

Best construction practices recommend placing HMA in a minimum of two layers. If placed in one layer, the joints tend to open, allowing water to travel through the mixture and into the underlying layers. Placing at least two layers allows the joint to be offset, resulting in a much reduced likelihood of water seeping through the asphalt layer into the underlying materials. This permeability issue often occurs, even when the joint meets density specifications. The joint in-place density is typically measured with a 4- or 6-in. diameter core; the measured density is the average density of the material volume contained in the core. The portion of the mixture directly on the joint has lower density, allowing water and air to penetrate through the mixture. In the long term, water percolation weakens the base, whereas air oxidizes the asphalt binder, resulting in stiffening of the binder properties and ultimate cracking and raveling at the joint (Brown et al. 2008). Placing the HMA layer in two lifts minimizes this type of issue at the joints.

Another problem occurring in flexible pavements is the lack of bond between HMA and the underlying layers. Past experience reported cases 
where slippage was caused by a lack of bond between layers (Brown et al. 2008). There were also instances where jet blast has picked up portions of HMA layer, detaching it from the pavement. Increasing the layer thickness will generally provide for a better bond and minimize the possibility of loss of material from jet blast.

From a thickness design standpoint, the cost increase, due to an increase in HMA thickness, can be somewhat offset by reducing the required thickness of the base course. In fact, the thickness needed to protect the subgrade can be divided between HMA and base layers with the only requirement for the asphalt thickness to suffice for base layer protection. More work on the slippage and blast effects are needed before identifying a value for minimum thickness for the HMA layer related to those considerations. 


\section{Conclusions}

The BETA approach offers a consistent methodology for determining minimum thickness that can be applied to evaluate each scenario in terms of tire pressure and granular layer CBR. The UFC criteria provide some guidance for minimum thickness, referencing it to specific aircraft types of load (light, medium, heavy, and modified heavy) and selected CBR values. The BETA approach supplements the UFC instructions by offering a consistent methodology for analyzing those cases not covered by the representative UFC tabulated values.

Aggregate gradation and construction practices may result in limitations on the minimum thickness of asphalt layer that can be built, independent from the structural requirements of the pavement. Based on past experience and numerous case studies, 4 in. is the recommended minimum thickness for the asphalt layer. Construction best practices suggest the placement of at least 4 in. of HMA in two lifts of 2 in. each with staggered joints. 


\section{References}

Ahlvin, D. 1991. Origin of developments for structural design of pavements. Technical Report GL-91-26. Vicksburg, MS: USAE Waterways Experiment Station.

Barker, W. R., and C. R. Gonzalez. 2006a. Renovation of the CBR design procedure. In Proceeding of Second International Airport Conference: Planning, Infrastructure \& Environment, 2-4 August 2006, Sao Paulo, Brazil.

Barker, W. R., and C. R. Gonzalez. 2006b. Implementation of a new flexible pavement design procedure for U.S. military airports. In Proceedings of Fourth LACCEI International Latin American and Caribbean Conference for Engineering and Technology (LACCEI'2006), "Breaking Frontiers and Barriers in Engineering: Education, Research and Practice," 21-23 J une 2006, Mayagüez, Puerto Rico.

Bell, H. P., and L. W. Mason. 2008. Evaluation of minimum asphalt thickness criteria. Technical Report TR-08-26. Vicksburg, MS: Engineer Research and Development Center.

Brown, E. R., M. R. Hainin, A. Cooley, and G. Hurley. 2004. Relationships of HMA inplace air voids, lift thickness, and permeability, Volumes I through IV. NCHRP Report No. 531. National Cooperative Highway Research Program.

Brown, E. R., M. Hainin, and L. Cooley, Jr. 2005. Determining minimum lift thickness for hot mix asphalt (HMA) mixtures. J ournal of the Association of Asphalt Paving Technologists 74:23-66. Long Beach, CA.

Brown, E. R., R. Ahlrich, R. Rollings, S. Muench, B. Prowell, A. Cooley, and R. J ames. 2008. Airfield asphalt pavement construction best practice manual. Airfield Asphalt Pavement Technology Program (AAPTP) Project 05-01. Auburn, AL: Auburn University.

Donovan, P., and E. Tutumluer. 2009. Effect of aircraft load wander on unbound aggregate pavement layer stiffness and deformation behavior. ASCE Conference Proceedings, Performance of Stabilized and Unbound Pavement Layers 329 (2008):40-53.

Donovan, P., and E. Tutumluer. 2009. Falling weight deflectometer testing to determine relative damage in asphalt pavement unbound aggregate layers. Transportation Research Record: J ournal of the Transportation Research Board 2104:12-23. Washington, DC: Transportation Research Board of the National Academies.

Tao, M., N. M. Louay, and D. N. Munir. 2010. Application of shakedown theory in characterizing traditional and recycled pavement base materials. J ournal of Transportation Engineering 136:214-223. 


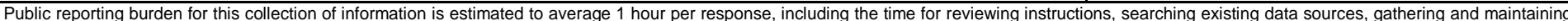

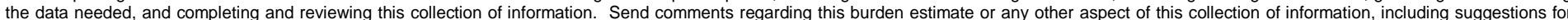

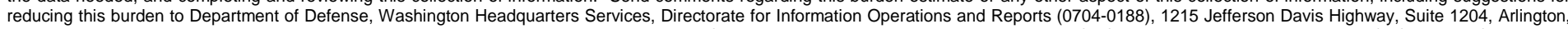

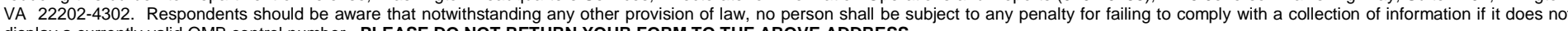
display a currently valid OMB control number. PLEASE DO NOT RETURN YOUR FORM TO THE ABOVE ADDRESS.
1. REPORT DATE (DD-MM-YYYY)
August 2011

\section{TITLE AND SUBTITLE}

Minimum Thickness Requirements for Asphalt Surface Course and Base Layer in Airfield Pavements
3. DATES COVERED (From - To)

5a. CONTRACT NUMBER

5b. GRANT NUMBER

5c. PROGRAM ELEMENT NUMBER

\section{AUTHOR(S)}

Walter R. Barker, Alessandra Bianchini, E. Ray Brown, and Carlos R. Gonzalez

\section{5d. PROJECT NUMBER}

5e. TASK NUMBER

\section{PERFORMING ORGANIZATION NAME(S) AND ADDRESS(ES)}

U.S. Army Engineer Research and Development Center

Geotechnical and Structures Laboratory

3909 Halls Ferry Road

Vicksburg, MS 39180-6199

\section{SPONSORING / MONITORING AGENCY NAME(S) AND ADDRESS(ES)}

Headquarters, U.S. Army Corps of Engineers

Washington, DC 20314-1000

5f. WORK UNIT NUMBER

8. PERFORMING ORGANIZATION REPORT NUMBER

ERDC/GSL TR-11-27

\section{DISTRIBUTION / AVAILABILITY STATEMENT}

Approved for public release; distribution is unlimited.

\section{SUPPLEMENTARY NOTES}

\section{ABSTRACT}

In designing flexible pavements for military airfields, minimum thicknesses of surface and base courses are given in the Unified Facilities Criteria (UFC) in tabular form based on the aircraft type, traffic area, and base California Bearing Ratio (CBR). With the development of larger and heavier aircraft, the minimum thickness requirements were simply adjusted upward through an empirical approach. In this report, the U.S. Army Engineer Research and Development Center (ERDC) research team proposes a rational methodology for determining minimum thicknesses for airfield pavements. The proposed procedure considers aircraft wheel loads, tire pressure, load repetitions, and the CBR of both base and subbase layers. In addition to presenting the methodology for determining layer minimum thicknesses from a structural standpoint, the manuscript briefly presents an examination of the effects of construction methods and materials on minimum thickness. Construction equipment and asphalt material characteristics directly influence the thickness of asphalt layer that can be constructed and its performance when subjected to traffic and the environment.

\section{SUBJECT TERMS}

Asphalt layer thickness

CBR

16. SECURITY CLASSIFICATION OF:

\begin{tabular}{|l|l|}
\hline a. REPORT & b. ABSTRACT \\
UNCLASSIFIED & UNCLASSIFIED
\end{tabular}

CBR-BETA procedure

Flexible pavement design

\begin{tabular}{|c|c|}
\hline & $\begin{array}{l}\text { 17. LIMITATION } \\
\text { OF ABSTRACT }\end{array}$ \\
\hline c. THIS PAGE & \\
\hline UNCLASSIFIED & \\
\hline
\end{tabular}

Minimum thickness

Soil strength

\begin{tabular}{c|l|}
$\begin{array}{c}\text { 18. NUMBER } \\
\text { OF PAGES }\end{array}$ & $\begin{array}{l}\text { 19a. NAME OF RESPONSIBLE } \\
\text { PERSON }\end{array}$ \\
\cline { 2 - 2 } 31 & $\begin{array}{l}\text { 19b. TELEPHONE NUMBER (include } \\
\text { area code) }\end{array}$ \\
&
\end{tabular}

